\title{
DO A SCIENCE EXPERIMENT FOR FUTURE SCIENTISTS
}

\section{Y. Kanematsu ${ }^{1}$, T. Matsumura ${ }^{2}$}

${ }^{1}$ Minerva Light Laboratory, 1-7 Hikaridai Seika, Soraku, Kyoto 619-0237, Japan mll.minerva@gmail.com

Keywords: microwave, chemical experiments, educational and voluntary activities.

It has been realized that various chemical reactions are accelerated under irradiation of MW. Such Microwave chemistry is known as timesaving, clear and eco-friendly. MW ovens are world-wide domestic tools for cooking which can serve meals quickly. Regardless of its convenience, few understand the essential mechanism of MW ovens. For better understanding of MW chemistry, authors think it is necessary for to introduce elementary knowledge by holding a 1-day program of experiments by using microwave (MW) ovens. "Science with microwave oven", 1-day program which we developed and named "Hirameki Tokimeki Science" was supported by Japan Society for the promotion of Science, has been performed over four years.More than 100 students of elementary and junior-high school have joined the program. Here we report the program, response from students.Program of experiments: "1: Dyeing handkerchief with onion peer $(* 1), 2$ : Cooking of pizza quickly yeast-leavened, 3: Preparation of shining slime with fluorescein dye synthesized in nonsolvent reaction. 4. Plasma in MW oven (*2), etc."Students realized how MW accelerated chemical reactions and that dyeing under MW was faster and more fixed compared with the conventional methods. Besides, they could enjoy lunch with pizza-and dealing with the slime, both they made. They had a good time with a bit of scientific knowledge.
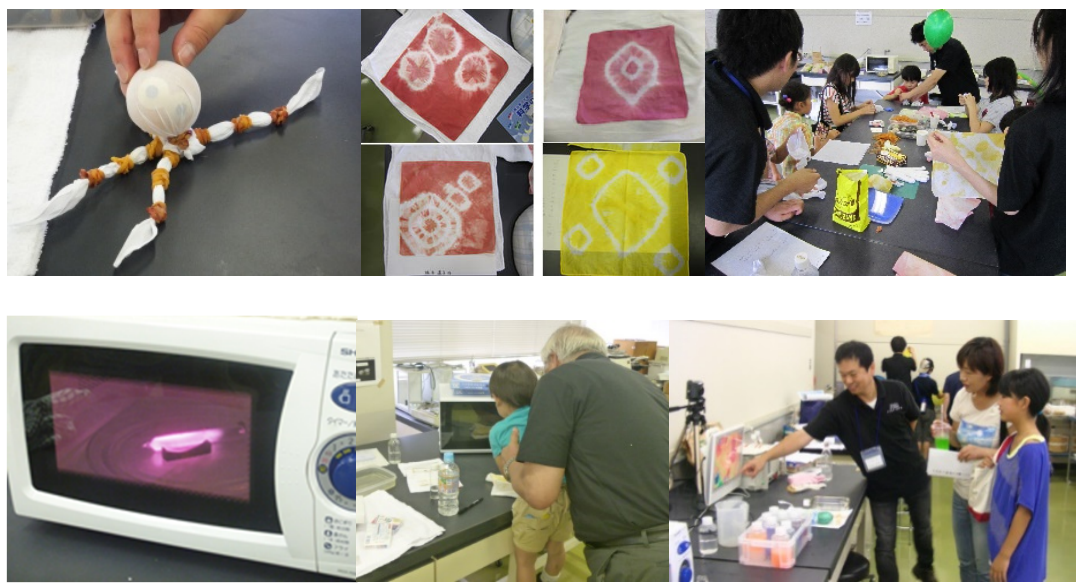

"Science with microwave oven" program surely gives students mysterious interest and dream for Science. That is "Inspire and Spark!" 
Through 1-day program, we can make science more familiar with students, and it will cause young students to become more interested in science, lead them to future research workers. In addition to the "Hirameki Tokimeki (Inspiration and Spark) Program, we have done Volunteer activities at Ishinomaki, one of the most damaged cities at the Higashi Nihon Big Earthquake, in 2011.

\section{Contents of Program}

\section{Introduction: What is microwave?}

2. Microwave plasma in microwave oven.

3. Speedy dying with plants.

4. Rapid cooking Pizza

5. Let's make shining slime!

6. Resume

\section{Introduction: What is microwave?}

Microwaves are a form of electromagnetic radiation with wavelengths ranging from about one meter to one millimeter; with frequencies between $300 \mathrm{MHz}(1 \mathrm{~m})$ and $300 \mathrm{GHz}(1 \mathrm{~mm})$.

One of the most familiar use of microwave is a mobile phone and a microwave oven. MW oven, discovered by American engineer, Percy Spencer of Raytheon Co. in 1946 has been spread over the world and used as kitchen appliance after Sharp Co. developed low-cost microwave oven with turn table in 1966. In this project, we use microwave oven to do microwave experiments in care with safety guide.

30 students, who joined the experiment, are divided into six groups, with one teaching assistant for each group.

\section{Microwave plasma in microwave oven}

The electricity of microwave oven. This experiment is aimed to realize the existence of electricity in a microwave oven. A core of sharp pencil, carbon fiber, sealed test tubes, are used.
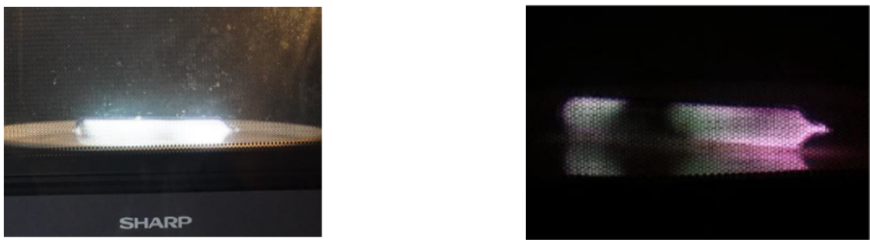

Brilliant 1 color of plasma in test tubes. 


\section{Procedure of dyeing with Plants}

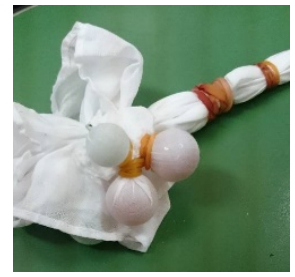

1. Design with chopstick marbles rubber bands

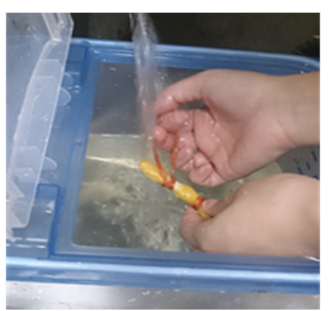

4.washing

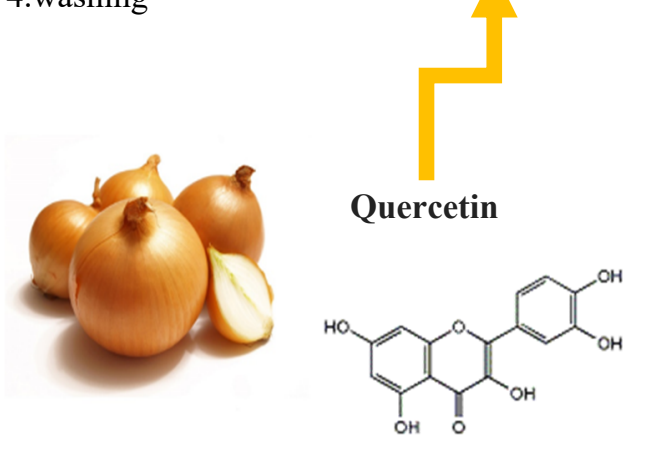

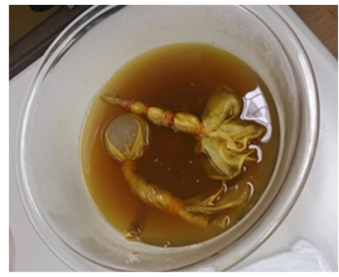

2. Immerse in the dyeing solution.

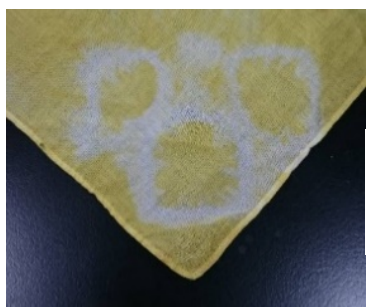

5. Dyed

Handkerchief

\section{Quercetin}

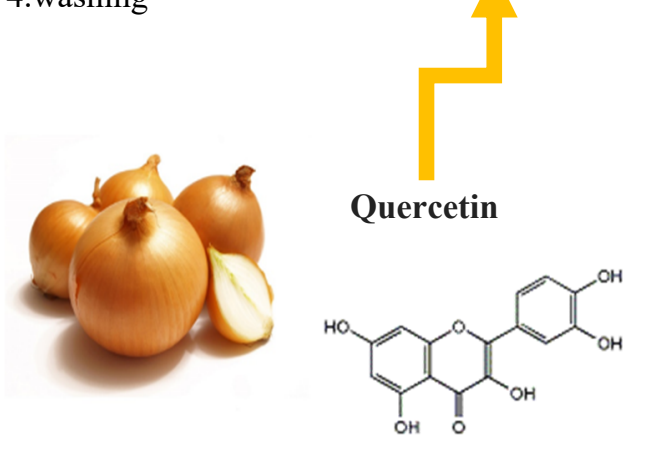

3. 5 minutes in an microwave oven 


\section{4 : Rapid cooking of Pizza}

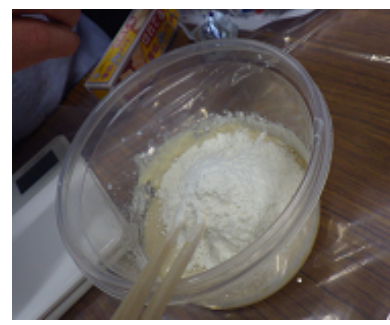

Mixing powder, milk, and butter

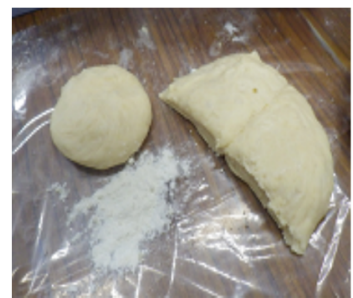

Punch the dough down

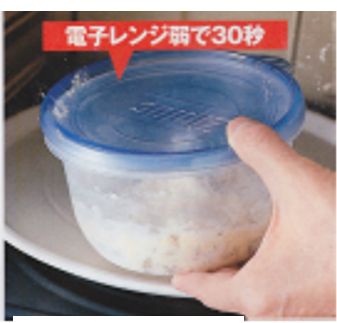

$30 \mathrm{sec}$.

in Oven

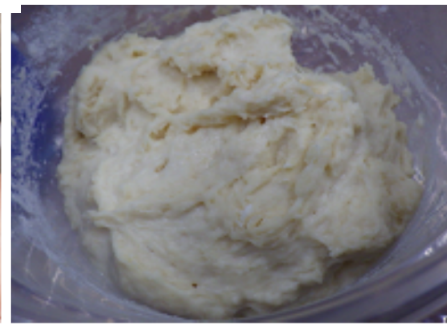

After 10min. the end of the first fermentation

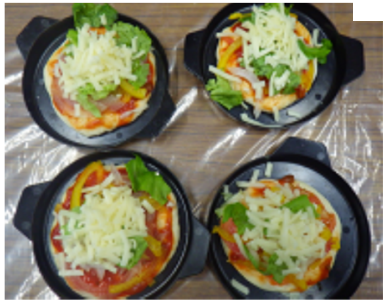

2 min. oven

Voila!

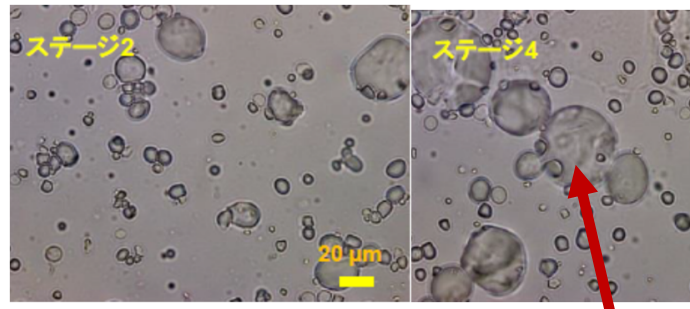

As fermentation proceeds, the number and

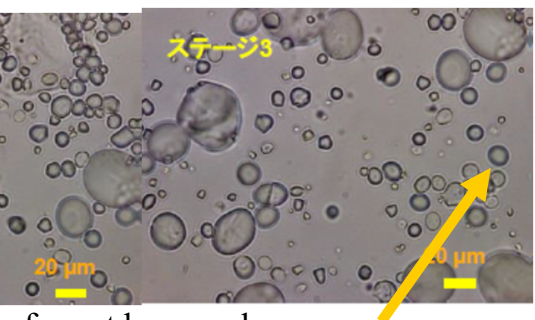

Large, awkward shapes are flour 


\section{5 : Let's make shining slime!}

Powdered phthalic anhydride and resorcinol were placed in a beaker and irradiated with $\mathrm{MW}(500 \mathrm{~W})$ without acid $\left(\mathrm{H}_{2} \mathrm{SO}_{4}\right)$. The powdered mixture started to melt in 2 minutes. The molten substance, became orange color in 3 minutes and red-orange in 5 minutes. Adding $\mathrm{Na}_{2} \mathrm{~B}_{4} \mathrm{O}_{7} \cdot 10 \mathrm{H}_{2} \mathrm{O}$, the color changes to brilliant green luminescent.<smiles>O=C1OC(=O)c2ccccc21</smiles>

Prehalic anhydride<smiles>Oc1ccccc1C=Cc1ccccc1O</smiles>

Hydroęcen bonded resorcinol dimer

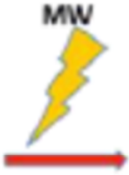

H
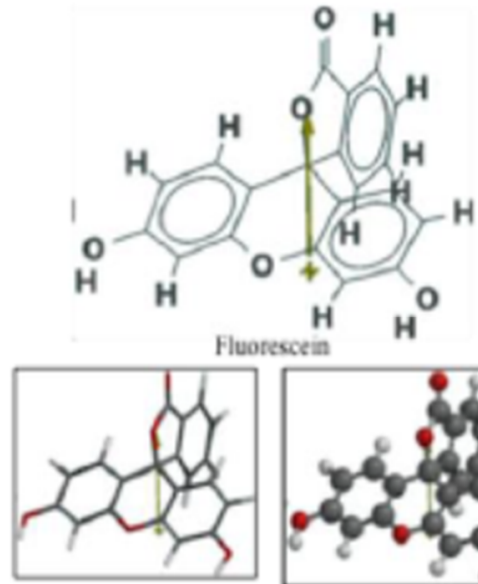

Tube model

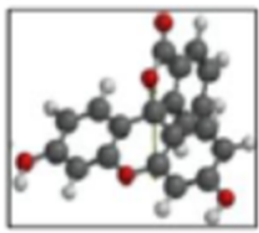

Ball and stick model

Mechanism of MW synthesis of fluorescein without catalyst.

\section{Let's make shining slime !}

Phtalic anhydride(A) and resorcinol(B) are microwaved to react chemically to $200^{\circ} \mathrm{C}$ and gives a sticky brown solution.

Mixture of $A$ and $B$ in a

bottle
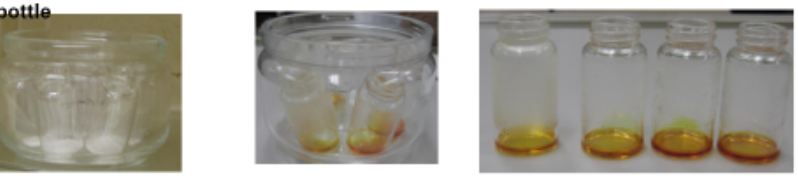

Before heating

Heating 3 minutes

Heating 6 minutes

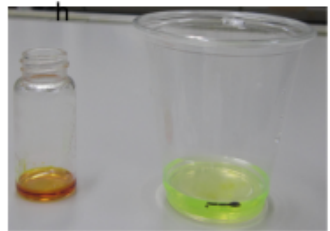

Add a bit of the solution into borax solution to emit $\Leftrightarrow$ Fluorescence Study conditions for emission
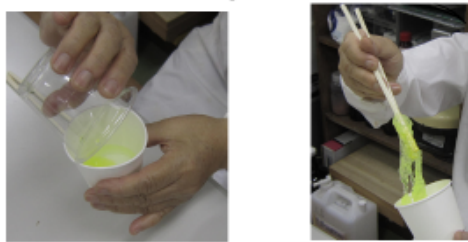

Add a portion of borax solution into laundry starch (polyvinyl alcohol) ) under stirring, the mixture gets hard. Add a bit of fluorescence produces shining slime 


\section{Resume for the study "DO A SCIENCE EXPERIMENT FOR FUTURE SCIENTISTS"}

After the experiment, Students accept the future doctoral degree from organizer.

Students are delight with new experience with microwave oven and surprised with the miracle activity of microwave science.

Thus, "Science with microwave oven" program surely gave students mysterious interest and dream for Science. That is "Inspire and Spark!"

\section{Acknowlegment}

We express our thanks to Teaching members of "Hirameki Tokimeki Science" and Volunteer members ISHINOMKI for their collaboration. 